\title{
One-year results of half-dose versus one- third-dose photodynamic therapy in chronic or recurrent central serous chorioretinopathy
}

\author{
Jirarattanasopa Pichai*, Banchasakjaroen Vanchalerm and Ratanasukon Mansing
}

\begin{abstract}
Background: Central serous chorioretinopathy (CSC) is characterized by an accumulation of subretinal fluid (SRF) in the macula. It is usually treated by laser photocoagulation or photodynamic therapy (PDT) with consisting of different doses and power. This study aimed to compare the efficacy of half-dose PDT and one-third-dose PDT in chronic or recurrent CSC.

Methods: A retrospective review of patients with chronic or recurrent CSC who were treated with either a halfdose or one-third-dose PDT, and had follow up 12 months afterwards. Best-corrected visual acuity (BCVA), central retinal thickness (CRT) and resolution of subretinal fluid (SRF) at baseline as well as 1, 3, 6 and 12 months post-PDT were assessed.

Results: Forty-six eyes and 20 eyes received half-dose and one-third-dose PDT, respectively. The study showed efficacy of the one-third-dose PDT compared with half-dose PDT in BCVA improvement $(0.10 \pm 0.04$ logMAR for onethird-dose versus $0.17 \pm 0.04$, for half-dose, $P=0.148$ ) and CRT improvement (125.6 $\pm 24.6 \mu \mathrm{m}$ for one-third-dose versus $139.1 \pm 16.54$, for half-dose, $P=0.933)$ at 12 months. The SRF recurrence rate was significantly higher in the one-thirddose PDT group compared with the half-dose PDT group (40.0\% versus $15.2 \%, P=0.027$ ) at 12 -months.

Conclusion: At 12 months, the one-third-dose PDT was effective in terms of BCVA and CRT improvement, when compared with half-dose PDT. However, this study showed that one-third-dose PDT had a higher recurrence rate of SRF.
\end{abstract}

Keywords: Photodynamic therapy (PDT), Half-dose PDT, One-third-dose PDT, Central serous chorioretinopathy (CSC)

\section{A brief summary statement}

At 12 months, the one-third-dose PDT was effective in term of BCVA and CRT improvement, when compared with half-dose PDT. However, this study showed that the one-third-dose PDT had a higher recurrence rate of SRF.

\footnotetext{
* Correspondence: jirarapichai@gmail.com

Department of Ophthalmology, Faculty of Medicine, Prince of Songkla University, Songkhla 90110, Thailand
}

\section{Background}

Central serous chorioretinopathy (CSC) is characterized by an accumulation of subretinal fluid (SRF) in the macula; with or without serous detachment of the retinal pigment epithelium (RPE), caused by choroidal vascular hyperpermeability $[1,2]$ Acute CSC spontaneously resolves within 3-4 months in most patients, but patients who have persistent or recurrent SRF require treatment [1-4].

(c) The Author(s). 2021 Open Access This article is licensed under a Creative Commons Attribution 4.0 International License, which permits use, sharing, adaptation, distribution and reproduction in any medium or format, as long as you give appropriate credit to the original author(s) and the source, provide a link to the Creative Commons licence, and indicate if changes were made. The images or other third party material in this article are included in the article's Creative Commons licence, unless indicated otherwise in a credit line to the material. If material is not included in the article's Creative Commons licence and your intended use is not permitted by statutory regulation or exceeds the permitted use, you will need to obtain permission directly from the copyright holder. To view a copy of this licence, visit http://creativecommons.org/licenses/by/4.0/ The Creative Commons Public Domain Dedication waiver (http://creativecommons.org/publicdomain/zero/1.0/) applies to the data made available in this article, unless otherwise stated in a credit line to the data. 
Laser photocoagulation is generally used to treat extrafoveal leakage. However, chronic CSC, with broad or indistinct leakage, and CSC with subfoveal or juxtafoveal leakage are difficult to treat with laser photocoagulation because of difficulty in localizing the leakage point. Additionally, there is the possibility of serious complications, such as RPE atrophy, permanent scotoma and secondary choroidal neovascularization (CNV) [4-7]. Photodynamic therapy (PDT) with verteporfin has been reported to be effective for reducing SRF; thereby improving the visual acuity in these patients [8-13]. However, post-PDT complications, such as RPE change, choroidal ischemia and secondary CNV [14-16], have motivated studies of the effect of lowering the dose of verteporfin, or decreasing the laser power energy (decreasing the fluence), so as to minimize post-PDT complications. Accordingly, many studies have reported the efficacy of half-dose PDT and half-fluence PDT in treatment of acute and chronic CSC, without serious complications [17-23].

Because of the variation in verteporfin doses being used for CSC, Zhao et al. [24, 25] performed a study showed that $30 \%$ verteporfin seemed to be safe and effective in the treatment of acute CSC. Due to issues with reimbursement, some patients in this study, conducted the Prince of Songkla University (PSU) hospital, were treated with onethird-dose PDT rather than half-dose PDT.

The purpose of this present study was to retrospectively compare the 1-year results for visual acuities, central retinal thickness (CRT), SRF and recurrence rate between half-dose PDT and onethird-dose PDT in patients with chronic or recurrent CSC.

\section{Methods}

We retrospectively reviewed medical records and images from patients who received half-dose PDT or one-thirddose PDT for chronic or recurrent CSC between January, 2012 and December, 2017; at the Department of Ophthalmology, Songklanagarind Hospital, PSU, Songkhla Province, Thailand. Our study was approved by the Institutional Review Board of Songklanagarind Hospital, PSU, and adhered to the guidelines of the Declaration of Helsinki.

We classified CSC into two types; chronic CSC; defined as based on symptoms persisting for longer than 3 months, and recurrent CSC; defined as based on new symptoms in the same eye of a patient with visual deficits from an earlier episode of CSC.

The inclusion criteria were as follows: (1) aged between 20 and 70 years; (2) chronic or recurrent CSC that was treated with half-dose PDT, or one-third-dose PDT; (3) presence of SRF involving the macula, as evident on spectral-domain optical coherence tomography (SD$\mathrm{OCT}$ ); and (4) the presence of active leakage on fluorescein angiography (FA).

The exclusion criteria were as follows: (1) previous PDT or intravitreal injections of anti-vascular endothelial growth factors (VEGF) or steroids; (2) previous intraocular surgery; (3) other macular abnormalities; such as $\mathrm{CNV}$, polypoidal choroidal vasculopathy (PCV) or other maculopathy; and (4) follow-up of less than 12 months, or missing data, including as best-corrected visual acuity (BCVA), OCT images at baseline, or 1, 3, 6 or 12 months after treatment.

The data collected included: patient gender, age, weight, height, laterality of visual impairment, duration of symptoms, type of CSC, leakage type of CSC on FA, spot size of PDT treatment, BCVA and CRT at baseline and at 1, 3, 6 and 12 months after treatment. The data were recorded from electronic medical records via the hospital information system, at the Department of Ophthalmology, Faculty of Medicine, PSU, Songkhla Province, Thailand.

The main outcome measures were the improvement in BCVA and CRT, and the presence of SRF at the 1-, 3-, 6- and 12-month follow-ups after PDT treatment. Evaluation of macular detachment and CRT were performed using an SD-OCT machine [(Spectralis ${ }^{\ominus}$ Heidelberg Engineering, Heidelberg, Germany) or (Cirrus $\mathrm{OCT}^{\circ}$, Carl Zeiss Meditec, Inc., Dublin, CA)]. We used the same machine for each patient during follow-ups. All patients underwent simultaneous FA and indocyanine green angiography (ICGA) [Heidelberg retinal angiography, Heidelberg Engineering, Heidelberg, Germany] at baseline, for confirmation of the diagnosis and planning of PDT treatment.

PDT was performed by administering a half-dose (3 $\left.\mathrm{mg} / \mathrm{m}^{2}\right)$, or one-third-dose $\left(2 \mathrm{mg} / \mathrm{m}^{2}\right)$ of verteporfin (Visudyne ${ }^{\circ}$, Novartis AG, Basel, Switzerland). All patients were randomized, by issue with reimbursement. Verteporfin was infused for $8 \mathrm{~min}$. The laser (wavelength $689 \mathrm{~nm}$, with a total light energy of $50 \mathrm{~J} / \mathrm{cm}^{2}$ for $83 \mathrm{~s}$ ), was delivered to the area of angiographic leakage observed on FA; with an associated area of choroidal hyperpermeability on ICGA at $10 \mathrm{~min}$ after infusion. After treatment, all patients were instructed to avoid sunlight for $48 \mathrm{~h}$. Informed consent for PDT was obtained from each patient, after having a discussion of the potential risks and benefits.

Statistical analysis was performed using SPSS (version 11.0, SPSS Inc., Chicago, IL). Linear fixed and random-effects models were used to compare BCVA and CRT between the two dosage groups, including the changes in BCVA and CRT within each group. The cumulative numbers of eyes with complete 
subretinal fluid reabsorption and recurrence of subretinal fluid were tested using Fisher exact test. $P$-values of $<0.05$ were considered statistically significant.

\section{Results}

A total of 87 patients with chronic or recurrent CSC were included. Twenty-seven patients were excluded because: their follow-up was less than 12 months (25 patients), the diagnosis was changed to PCV (1 patient) or their follow-up OCT data were missing (1 patient). Finally, data from 60 patients (66 eyes) were analyzed. From this, 41 patients (46 eyes) had received half-dose PDT and 19 patients (20 eyes) had received one-thirddose PDT (Fig. 1).

The baseline demographic data and clinical characteristics of the patients in the two treatment groups are summarized in Table 1 . There were no statistically significant differences in gender, laterality, body mass index, duration of symptoms, type of CSC, leakage type on FA, spot size of PDT, initial BCVA or CRT. However, the half-dose PDT group was older than the one-thirddose PDT group $(P=0.03)$.

\section{Changes in BCVA}

The half-dose PDT group showed statistically significant BCVA improvement at 1, 3, 6 and 12 months after PDT treatment when compared with the baseline (Table 2). In the one-third-dose PDT group, BCVA showed statistically significant improvement at 6 and 12 months after PDT treatment, when compared with the baseline.

When the two groups were compared, the half-dose PDT group did not show a statistically significant difference in BCVA (Table 2), or in BCVA improvement (Table 3) at 1, 3, 6 and 12 months; relative to the onethird-dose PDT group.

\section{Changes in CRT}

Both groups showed statistically significant reductions in CRT, compared with the baseline, at 1, 3, 6 and 12 months after PDT treatment (Table 4). In contrast, the half-dose PDT group did not show statistically significantly differences in CRT or CRT reduction at 1, 3, 6 and 12 months, compared with the one-third-dose PDT group at these times (Tables 4 and 5).

\section{The accumulated number of eyes with complete SRF reabsorption after a single PDT treatment}

In both groups, all eyes had evidence of SRF reabsorption within 12 months after a single PDT treatment (Table 6).

\section{The cumulative number of eyes with recurrence of SRF after a single PDT treatment}

In the half-dose PDT group, the accumulated numbers of eyes with recurrence of SRF after achieving a dry macula were 2 (4.3\%), 4(8.7\%) and $7(15.2 \%)$ within 3, 6 and 12 months after a single PDT treatment (Table 7). Two eyes had recurrent SRF within 3 months and were successfully treated with a repeated half-dose PDT. Two eyes had recurrence within 6 months; one was successfully treated with focal laser, while the other spontaneously resolved with observation.

In the one-third-dose PDT group, the cumulative numbers of eyes with recurrent SRF after a dry macula,

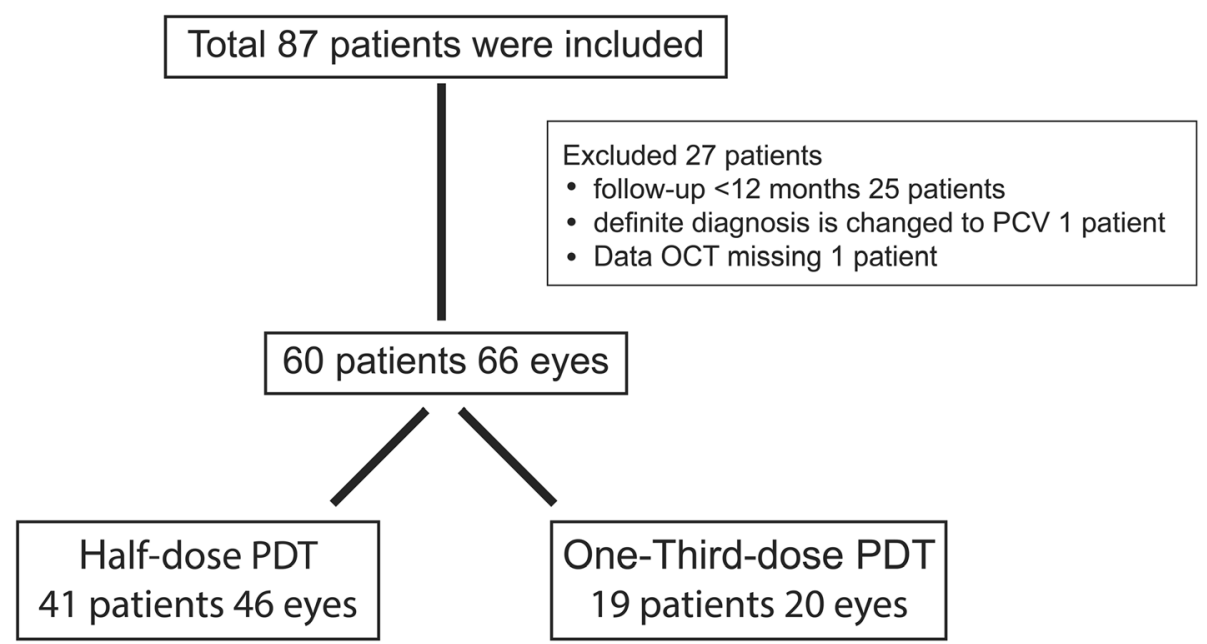

Fig. 1 Flowchart of patients and eyes included in, and excluded, from the study. Abbreviations: OCT, optical coherence tomography: PCV, polypoidal choroidal vasculopathy: PDT, photodynamic theraphy 
Table 1 Comparison of demographic data for the two treatment groups

\begin{tabular}{|c|c|c|c|}
\hline Characteristic & $\begin{array}{l}\text { Half-dose PDT group ( } n=46 \text { eyes } / 41 \\
\text { patients) }\end{array}$ & $\begin{array}{l}\text { One-third-dose PDT group ( } n=20 \text { eyes } / 19 \\
\text { patients) }\end{array}$ & $\begin{array}{l}P \text { - } \\
\text { value }\end{array}$ \\
\hline Age, mean $\pm S D$ (years) & $51.51 \pm 7.8$ & $46.47 \pm 8.88$ & $0.030^{*}$ \\
\hline \multicolumn{4}{|l|}{ Sex, No. (\%) } \\
\hline -Male & $29(70.7)$ & $15(78.9)$ & \multirow[t]{2}{*}{0.754} \\
\hline -Female & $12(29.3)$ & $4(21.1)$ & \\
\hline \multicolumn{4}{|l|}{ Study eye, No. (\%) } \\
\hline -Right & $25(54.3)$ & $10(50.0)$ & \multirow[t]{2}{*}{0.793} \\
\hline -Left & $21(45.7)$ & $10(50.0)$ & \\
\hline $\mathrm{BMI}$, mean $\pm \mathrm{SD}, \mathrm{kg} / \mathrm{m}^{2}$ & $24.07 \pm 3.80$ & $24.06 \pm 3.18$ & 0.994 \\
\hline $\begin{array}{l}\text { Duration of symptoms, mean } \pm \mathrm{SD} \text {, } \\
\text { (months) }\end{array}$ & $9.43 \pm 8.84$ & $12.35 \pm 8.13$ & 0.212 \\
\hline \multicolumn{4}{|l|}{ Group types, No. (\%) } \\
\hline -Chronic & $39(84.8)$ & $13(65.0)$ & \multirow[t]{2}{*}{0.071} \\
\hline -Recurrent & $7(15.2)$ & $7(35.0)$ & \\
\hline \multicolumn{4}{|l|}{ Leakage type, No. (\%) } \\
\hline -Smoke stack & $8(17.4)$ & $3(15.0)$ & \multirow[t]{3}{*}{0.652} \\
\hline -Ink blot & $27(58.7)$ & $14(70.0)$ & \\
\hline -Diffuse & $11(23.9)$ & $3(15.0)$ & \\
\hline GLD mean $\pm S D(\mu m)$ & $1324.50 \pm 1510.09$ & $1957.70 \pm 1122.72$ & 0.980 \\
\hline PDT spot size, mean \pm SD $(\mu m)$ & $2438.04 \pm 1649.09$ & $3155.40 \pm 1450.59$ & 0.980 \\
\hline \multicolumn{4}{|l|}{ Initial BCVA } \\
\hline -LogMAR, mean $\pm S D$ & $0.40 \pm 0.37$ & $0.40 \pm 0.41$ & 0.908 \\
\hline Initial CRT, mean $\pm S D(\mu m)$ & $366.57 \pm 127.69$ & $352.90 \pm 107.10$ & 0.677 \\
\hline
\end{tabular}

Abbreviations: $B C V A$ best corrected visual acuity; $B M I$ body mass index, $C R T$ central retinal thickness; GLD greatest linear diameter; LogMAR logarithm of the minimum angle of resolution, $P D T$ photodynamic therapy, $S D$ standard deviation

were $1(5 \%), 5(25 \%)$ and $8(40 \%)$ within 3,6 and 12 months after PDT treatment. One eye had a recurrence within 3 months and was successfully treated with a repeated one-third-dose PDT. Four eyes had SRF recurrence within 6 months. In 3 cases, these were successfully treated with a repeated one-third-dose PDT.
The other case spontaneously resolved after observation. In both groups, three eyes had recurrence of SRF at their 12-month follow up.

The one-third-dose PDT group showed a significantly, higher recurrence rate than that of the half-dose PDT group at 12 months $(P=0.027)$ (Table 7$)$.

Table 2 The best corrected visual acuity (BCVA) results from patients with chronic or recurrent central serous chorioretinopathy before and after different doses of photodynamic therapy

\begin{tabular}{|c|c|c|c|}
\hline LogMAR BCVA & Half-dose $^{(1)}($ mean \pm SD $)$ & One-third-dose $^{(2)}($ mean $\pm S D)$ & $P$-value ${ }^{(1)-(2)}$ \\
\hline At baseline ${ }^{a}$ & $0.41 \pm 0.37$ & $0.40 \pm 0.41$ & 0.893 \\
\hline At 1 month ${ }^{\text {b }}$ & $0.32 \pm 0.34$ & $0.36 \pm 0.41$ & 0.690 \\
\hline At 3 months ${ }^{c}$ & $0.29 \pm 0.33$ & $0.35 \pm 0.41$ & 0.623 \\
\hline At 6 months ${ }^{d}$ & $0.24 \pm 0.32$ & $0.31 \pm 0.36$ & 0.541 \\
\hline At 12 months ${ }^{e}$ & $0.24 \pm 0.34$ & $0.30 \pm 0.43$ & 0.526 \\
\hline P-value & $\begin{array}{l}a-b ; p=0.002, a-c, p<0.001 \\
a-d, p<0.001, a-e, p<0.001\end{array}$ & $\begin{array}{l}a-b ; p=0.419, a-c, p=0.216 \\
a-d ; p=0.038, a-e ; p=0.028\end{array}$ & \\
\hline
\end{tabular}

a,b,c,d: Linear fixed- and random-effects models

(1)-(2): Linear fixed- and random-effects models

Abbreviations: $S D$ standard deviation 
Table 3 Best corrected visual acuity (BCVA) improvement in patients with chronic or recurrent central serous chorioretinopathy after different doses of photodynamic therapy

\begin{tabular}{llll}
\hline BCVA improvement (LogMAR) & Half dose $($ mean \pm SD) & One-third dose (mean \pm SD) & $P_{\text {-value }}{ }^{\text {a }}$ \\
\hline VA 1 month - VA Initial & $-0.09 \pm 0.26$ & $-0.04 \pm 0.13$ & 0.317 \\
VA 3 month - VA Initial & $-0.11 \pm 0.27$ & $-0.05 \pm 0.15$ & 0.244 \\
VA 6 month - VA Initial & $-0.16 \pm 0.30$ & $-0.09 \pm 0.14$ & 0.161 \\
VA 12 month - VA Initial & $-0.17 \pm 0.29$ & $-0.10 \pm 0.17$ & 0.148 \\
\hline
\end{tabular}

${ }^{a}$ Linear fixed- and random-effects models

Abbreviations: BCVA best corrected visual acuity, LogMAR logarithm of the minimum angle of resolution;

$S D$ standard deviation

The comparison of demographic data of the patients with recurrence of subretinal fluid, after photodynamic therapy, between the two treatment groups

The comparison of demographic data of the patients with recurrence of subretinal fluid after photodynamic therapy, between the two treatment groups is summarized in Table 8 . There were no statistically significant differences in age, gender, laterality, body mass index, duration of symptoms, type of CSC, leakage type on FA, spot size of PDT, initial BCVA and initial CRT.

After recurrence SRF, with a single PDT, 6/7 eyes in the half-dose PDT groups and 7/8 eyes in the one-thirddose PDT group were reperformed FA. In the half-dose PDT group, the $5 / 6$ eyes and $1 / 6$ eyes consisted of leaks in area having been previously treated, and de-novo leakage, respectively. In the one-third-dose PDT group, the $6 / 7$ eyes and $1 / 7$ eyes consisted of leaks in area having been previously treated and de-novo leakage, respectively.

\section{Safety}

There were no patients in either group who had an allergic reaction to verteporfin, and there were no ocular adverse events; including any development of secondary $\mathrm{CNV}$, during the follow-up periods.

\section{Discussion}

CSC is characterized by an accumulation of SRF in the macula, with or without serous detachment of the RPE, caused by choroidal vascular hyperpermeability [1, 2]. PDT is applied for treatment of CSC because it acts to reconstruct the choroidal vasculature and reduce vascular hyperpermeability [8-13]. Recently, the PDT protocol has been modified to reduce the rate of complications, by reducing the dosage of verteporfin or reducing the fluence [17-23]. However, to-date, the optimal PDT protocol for maintaining efficacy, and reducing adverse events remains unclear. This retrospective study compared the efficacy of one-third-dose and half-dose PDT for chronic, or recurrent CSC.

The reduction of CRT in this study was similar to that in previous studies $[17,23-26]$. The previous studies using half-dose PDT [17, 23, 26] showed that the CRT reduction was significant from 1 month, until 12-months of follow-up. Similarly, in previous studies using one-third-dose PDT, Zhoa et al. [24, 25] showed that CRT was significantly reduced from 1 month to the 12-months of follow-up. In our study, both half-dose and one-third-dose PDT were effective in reducing CRT in both chronic and recurrent CSC from, 1 month until 12 months after treatment.

Table 4 The central retinal thickness (CRT) in patients with chronic or recurrent central serous chorioretinopathy before and after different doses of photodynamic therapy

\begin{tabular}{|c|c|c|c|}
\hline CRT $(\mu \mathrm{m})$ & Half-dose $^{(1)}($ mean $\pm S D)$ & One-third-dose ${ }^{(2)}($ mean $\pm S D)$ & $P$-value ${ }^{(1)-(2)}$ \\
\hline At baseline $^{a}$ & $366.57 \pm 127.69$ & $352.90 \pm 107.10$ & 0.501 \\
\hline At 1 month ${ }^{b}$ & $237.48 \pm 57.92$ & $221.55 \pm 38.15$ & 0.434 \\
\hline At 3 months ${ }^{c}$ & $244.39 \pm 84.14$ & $222.11 \pm 31.76$ & 0.290 \\
\hline At 6 months ${ }^{d}$ & $227.87 \pm 48.91$ & $228.85 \pm 55.54$ & 0.949 \\
\hline At 12 months $^{\mathrm{e}}$ & $227.46 \pm 52.20$ & $227.35 \pm 34.78$ & 0.758 \\
\hline P-value & $a-b, a-c, a-d, a-e ; p<0.001$ & $a-b, a-c, a-d, a-e ; p<0.001$ & \\
\hline
\end{tabular}

$\overline{\mathrm{a}, \mathrm{b}, \mathrm{c}, \mathrm{d}}$ : Linear fixed- and random-effects models

(1)-(2): Linear fixed- and random-effects models

Abbreviations: CRT central retinal thickness, SD standard deviation 
Table 5 Central retinal thickness (CRT) reduction in patients with chronic or recurrent central serous chorioretinopathy after different doses of photodynamic therapy

\begin{tabular}{llll}
\hline Mean CRT reduction $(\boldsymbol{\mu m})$ & Half dose $($ mean \pm SD) & One-third dose $($ mean \pm SD) & $\boldsymbol{P}_{\text {-value }}{ }^{\mathbf{a}}$ \\
\hline CST Initial - CST 1 month & $129.09 \pm 119.96$ & $131.35 \pm 107.81$ & 0.926 \\
CST Initial - CST 3 months & $122.17 \pm 137.57$ & $132.63 \pm 107.63$ & 0.738 \\
CST Initial - CST 6 months & $139.31 \pm 118.72$ & $124.05 \pm 112.48$ & 0.536 \\
CST Initial - CST 12 months & $139.11 \pm 112.16$ & $125.55 \pm 110.07$ & 0.933 \\
\hline
\end{tabular}

${ }^{a}$ Linear fixed- and random-effects models

Abbreviations: CRT central retinal thickness, SD standard deviation

Uetani et al. [27] reported that the SRF reabsorption rates were 70 and $33 \%$ at 1 month after treatment with half-dose and one-third-dose PDT, respectively, in patients with chronic CSC. Similarly, Zhoa et al. [25] reported that the SRF reabsorption rates were 92.9 and $73.8 \%$ at 6 months after treatment with a single halfdose and one-third-dose PDT, respectively, in chronic CSC. In our study, the same tendency was observed. The half-dose PDT group showed a higher percentage of eyes with SRF reabsorption than that of the one-third-dose PDT group (72\% versus 60\%; although the difference was not significant), at 1-month post-treatment. Because of the small number of eyes in this study, the speed with which SRF reabsorption occurred after PDT in the two groups requires further study.

The BCVA improvements observed in this study were similar to that in previous studies $[17,23-26]$. Previous studies using half-dose PDT $[17,23,28]$ showed that BCVA was significantly improved at 12 months after PDT. Similarly, a study by Zhoa et al. [25]; using onethird-dose PDT, showed significant improvement in BCVA at the 12-month follow-up period. In our study,

Table 6 The cumulative number of eyes with complete subretinal fluid reabsorption after a single photodynamic therapy treatment (PDT)

\begin{tabular}{llll}
\hline Outcome & $\begin{array}{l}\text { Half-dose PDT } \\
\text { group N (\%) }\end{array}$ & $\begin{array}{l}\text { One-third-dose PDT } \\
\text { group } \boldsymbol{N}(\%)\end{array}$ & $\begin{array}{l}\boldsymbol{P} \text { - } \\
\text { value }\end{array}$ \\
\hline $\begin{array}{l}\text { At } 1 \text { month } \\
\begin{array}{l}\text { Completely } \\
\text { reabsorbed }(n, \%)\end{array}\end{array}$ & $33(72 \%)$ & $12(60 \%)$ & 0.347 \\
$\begin{array}{l}\text { At } 3 \text { months } \\
\text { Completely } \\
\text { reabsorbed }(n, \%)\end{array}$ & $39(85 \%)$ & $17(85 \%)$ & 0.982 \\
$\begin{array}{l}\text { At } 6 \text { months } \\
\text { Completely } \\
\text { reabsorbed }(n, \%)\end{array}$ & $44(96 \%)$ & $19(95 \%)$ & 0.907 \\
$\begin{array}{l}\text { At } 12 \text { months } \\
\begin{array}{l}\text { Completely } \\
\text { reabsorbed }(n, \%)\end{array}\end{array}$ & $46(100 \%)$ & $20(100 \%)$ & \\
\hline
\end{tabular}

both half-dose and one-third-dose PDT were effective in improving BCVA in chronic, or recurrent CSC at 12 months. However, the half-dose PDT group showed faster BCVA improvement than that of the one-third-dose PDT group. This result may be due to the higher percentage of early SRF reabsorption in the half-dose PDT group.

Many previous studies [17, 23] have reported 1-year recurrence rates of SRF in half-dose PDT of approximately $8.3-13.2 \%$. In our study, the rates were $15.2 \%$ in the half-dose PDT group and $40 \%$ in the onethird-dose PDT group. We postulate that the higher recurrence rate in the one-third-dose PDT group may have been caused by the lower effect on choroidal remodeling and choroidal hyperpermeability with reduced doses of verteporfin. However, the changes in choroidal thickness after different doses of PDT should be demonstrated in further studies.

This study showed that one-third-dose PDT was effective in the treatment of chronic or recurrent CSC. However, our study also showed that the recurrence rate with the one-third-dose was significantly higher than that in the half-dose PDT within 1 year after treatment. Therefore, in cases of chronic or recurrent CSC, half-dose PDT should be recommended, more so than the one-third dose regimen. The limitations of this study are its retrospective nature, having a small sample size in the one-third-dose PDT group, and the lack of comparison of choroidal thicknesses between groups.

Table 7 The cumulative numbers of eye with recurrence of subretinal fluid (SRF) after a single photodynamic therapy treatment (PDT)

\begin{tabular}{llll}
\hline $\begin{array}{l}\text { Recurrent } \\
\text { SRF }\end{array}$ & $\begin{array}{l}\text { One-third-dose PDT } \\
\text { group } \boldsymbol{N}(\%)\end{array}$ & $\begin{array}{l}\text { Half-dose PDT } \\
\text { group } \boldsymbol{N}(\%)\end{array}$ & $\begin{array}{l}\boldsymbol{P} \text { - } \\
\text { value }\end{array}$ \\
\hline $\begin{array}{l}\text { Within 3 } \\
\text { months }\end{array}$ & $1(5 \%)$ & $2(4.3 \%)$ & 0.907 \\
$\begin{array}{l}\text { Within 6 } \\
\text { months }\end{array}$ & $5(25 \%)$ & $4(8.7 \%)$ & 0.076 \\
$\begin{array}{l}\text { Within 12 } \\
\text { months }\end{array}$ & $8(40 \%)$ & $7(15.2 \%)$ & $0.027^{*}$ \\
\hline
\end{tabular}


Table 8 Comparison of demographic data for patients with recurrence of subretinal fluid, after photodynamic therapy, between the two treatment groups

\begin{tabular}{|c|c|c|c|}
\hline Demographic $(N=15)$ & $\begin{array}{l}\text { Half-dose PDT group ( } n=7 \text { eyes/ } \\
\text { 5patients) }\end{array}$ & $\begin{array}{l}\text { One-third-dose PDT group ( } n=8 \text { eyes } / 7 \\
\text { patients) }\end{array}$ & $\begin{array}{l}P \text { - } \\
\text { Value }\end{array}$ \\
\hline Age mean \pm sd (years) & $52.00 \pm 6.44$ & $48.14 \pm 9.99$ & 0.469 \\
\hline \multicolumn{4}{|l|}{ Sex,No.(\%) } \\
\hline Male & $5(100)$ & $7(100)$ & \multirow[t]{2}{*}{-} \\
\hline Female & $0(0.0)$ & $0(0.0)$ & \\
\hline \multicolumn{4}{|l|}{ Study eye, No. (\%) } \\
\hline RE & $4(57.1)$ & $3(37.5)$ & \multirow[t]{2}{*}{0.619} \\
\hline LE & $3(42.9)$ & $5(62.5)$ & \\
\hline $\mathrm{BMI}, \mathrm{mean} \pm \mathrm{sd}, \mathrm{kg} / \mathrm{m}^{2}$ & $23.81 \pm 6.85$ & $24.99 \pm 3.30$ & 0.697 \\
\hline $\begin{array}{l}\text { duration of symptom, mean } \pm \text { sd, } \\
\text { (months) }\end{array}$ & $15.00 \pm 11.59$ & $16.25 \pm 8.69$ & 0.815 \\
\hline \multicolumn{4}{|l|}{ Group Type } \\
\hline recurrent & $0(0.0)$ & $3(37.5)$ & \multirow[t]{2}{*}{0.200} \\
\hline chronic recurrent & $7(100)$ & $5(62.5)$ & \\
\hline \multicolumn{4}{|l|}{ Leakage type, No. (\%) } \\
\hline Smoke stack & $0(0.0)$ & $1(12.5)$ & \multirow[t]{3}{*}{0.348} \\
\hline Ink blot & $2(28.6)$ & $4(50.0)$ & \\
\hline Diffuse & $5(71.4)$ & $3(37.5)$ & \\
\hline GLP (mean $\pm s d)$ & $2187.14 \pm 1901.31$ & $2339.00 \pm 1457.98$ & 0.864 \\
\hline PDT spot size, (mean \pm sd) & $3514.29 \pm 2132.62$ & $3638.38 \pm 2080.62$ & 0.911 \\
\hline \multicolumn{4}{|l|}{ Initial BCVA } \\
\hline LogMAR, (mean \pm sd) & $0.62 \pm 0.38$ & $0.30 \pm 0.33$ & 0.099 \\
\hline Initial CRT, (mean \pm sd) & $321.00 \pm 135.67$ & $288.25 \pm 60.02$ & 0.546 \\
\hline
\end{tabular}

Abbreviations: $B C V A$ best corrected visual acuity; BMI body mass index, CRT central retinal thickness, GLD greatest linear diameter; LogMAR, logarithm of the minimum angle of resolution, $P D T$ photodynamic therapy, $S D$ standard deviation

\section{Conclusion}

In conclusion, these 1-year results show one-third-dose PDT was effective in term of BCVA and CRT improvement when compared with half-dose PDT. However, the one-third-dose PDT had a higher recurrent rate of disease.

\section{Abbreviations}

PDT: Photodynamic therapy; CSC: Central serous chorioretinopathy;

BCVA: Best-corrected visual acuity; CRT: Central retinal thickness;

SRF: Subretinal fluid; RPE: Retinal pigment epithelium; CNV: Choroidal

neovascularization; SD-OCT: Spectral-domain optical coherence tomography;

FA: Fluorescein angiography; VEGF: Vascular endothelial growth factor;

PCV: Polypoidal choroidal vasculopathy; ICGA: Indocyanine green

angiography

\section{Acknowledgements}

The research was partially supported by a grant from Faculty of Medicine, Prince of Songkla University. We would like to thank Ms. Jirawan Jayuphan for the statistics analyzed and Mr. Andrew Jonathan Tait, from the International Affairs department, for editing of the English in this paper. We also would like to thank Ms. Parichat Damthongsuk and Ms. Sujinda Damthong for their assistance in collecting the data.

\section{Meeting presentation}

This paper was presented at the World Eye AND Vision Congress; December 9-102,019; Dubai, UAE.

\section{Authors' contributions}

JP; designed the study, analyzed and interpreted the data, wrote and revised the manuscript. BV; was responsible for data acquisition, analyzed the data and wrote the manuscript. RM; was responsible for conception and design and revised the manuscript. The final manuscript has been read and approved by all authors.

\section{Funding}

Faculty of Medicine, Prince of Songkla University.

\section{Availability of data and materials}

The datasets used and/or analyzed during the current study are available from the corresponding author upon reasonable request.

\section{Ethics approval and consent to participate}

In this study was approved by the Institutional Review Board of Songklanagarind Hospital, Faculty of Medicine, Prince of Songkla University, and adhered to the guidelines of the Declaration of Helsinki. For this type of study formal consent was waived.

Consent for publication

Not applicable.

Competing interests

The authors declare that they have no competing interests. 
Received: 24 June 2020 Accepted: 29 December 2020

Published online: 12 January 2021

\section{References}

1. Ciardella AP, Guyer DR, Spitznas M, Yannuzzi LA. Central serous chorioretinopathy. In: Ryan SJ, editor. Retina. St Louis: Mosby; 2001. p. 1153-81.

2. Nicholson B, Noble J, Forooghiean F, Meyerle C. Central serous chorioretinopathy: Update on pathophysiology and treatment. Surv Ophthalmol. 2013:58:103-26.

3. Gilbert CM, Owens SL, Smith PD, Fine SL. Long-term follow-up of central serous chorioretinopathy. Br J Ophthalmol. 1984;68:815-20.

4. Brancato R, Scialdone A, Pece A, Coscas G, Binaghi M. Eight-year follow-up of central serous chorioretinopathy with and without laser treatment. Graefes Arch Clin Exp Ophthalmol. 1987;225:166-8.

5. Leaver $P$, Williams $C$. Argon laser photocoagulation in the treatment of central serous retinopathy. Br J Ophthalmol. 1979;63:674-7.

6. Ficker L, Vafidis $G$, While A, Leaver P. Long-term follow-up of a prospective trial of argon laser photocoagulation in the treatment of central serous retinopathy. Br J Ophthalmol. 1988;72:829-34.

7. Burumcek E, Mudun A, Karacorlu S, Arslan MO. Laser photocoagulation for persistent central serous retinopathy: results of long-term follow-up. Ophthalmology. 1997;104:616-22

8. Chan WM, Lam DS, Lai TY, Tam BS, Liu DT, Chan CK. Choroidal vascular remodeling in central serous chorioretinopathy after indocyanine green guided photodynamic therapy with verteporfin: a novel treatment at the primary disease level. Br J Ophthalmol. 2003:87:1453-8.

9. Yannuzzi LA, Slakter JS, Gross NE, Spaide RF, Costa D, Huang SJ, et al. Indocyanine green angiography-guided photodynamic therapy for treatment of chronic central serous chorioretinopathy: a pilot study. Retina. 2003;23:288-98

10. Cardillo Piccolino F, Eandi CM, Ventre L, Rigault de la Longrais RC, Grignolo FM. Photodynamic therapy for chronic central serous chorioretinopathy. Retina. 2003:23:752-63.

11. Erikitola OC, Crosby-Nwaobi R, Lotery AJ, Sivaprasad S. Photodynamic therapy for central serous chorioretinopathy. Eye. 2014:28:944-57.

12. Taban M, Boyer DS, Thomas EL, Taban M. Chronic central serous chorioretinopathy: photodynamic therapy. Am J Ophthalmol. 2004;137: 1073-80.

13. Ober MD, Yannuzzi LA, Do DV, Spaide RF, Bressler NM, Jampol LM, et al. Photodynamic therapy for focal retinal pigment epithelial leaks secondary to central serous chorioretinopathy. Ophthalmology. 2005;112:2088-94.

14. Klais CM, Ober MD, Freund KB, Ginsburg LH, Luckie A, Mauget-Faysse M, et al. Choroidal infarction following photodynamic therapy with verteporfin. Arch Ophthalmol. 2005;123:1149-53.

15. Lee PY, Kim KS, Lee WK. Severe choroidal ischemia following photodynamic therapy for pigment epithelial detachment and chronic central serous chorioretinopathy. Jpn J Ophthalmol. 2009;53:52-6.

16. Colucciello M. Choroidal neovascularization complicating photodynamic therapy for central serous retinopathy. Retina. 2006;26:239-42.

17. Chan WM, Lai TY, Lai RY, Tang EW, Liu DT, Lam DS. Safety enhanced photodynamic therapy for chronic central serous chorioretinopathy: oneyear results of a prospective study. Retina. 2008;28:85-93.

18. Chan WM, Lai TY, Lai RY, Liu DT, Lam DS. Half-dose verteporfin photodynamic therapy for acute central serous chorioretinopathy: one-year results of a randomized controlled trial. Ophthalmology. 2008;115:1756-65.

19. Reibaldi M, Boscia F, Avitabile T, Russo A, Cannemi V, Uva MG, et al. Lowfluence photodynamic therapy in longstanding chronic central serous chorioretinopathy with foveal and gravitational atrophy. Eur J Ophthalmol. 2009;19:154-8.

20. Reibaldi M, Cardascia N, Longo A, Furino C, Avitabile T, Faro S, et al. Standard-fluence versus low-fluence photodynamic therapy in chronic central serous chorioretinopathy: a nonrandomized clinical trial. Am. J Ophthalmol. 2010;149:307-15.

21. Shin JY, Woo SJ, Yu HG, Park KH. Comparison of efficacy and safety between half-fluence and full-fluence photodynamic therapy for chronic central serous chorioretinopathy. Retina. 2011:31:119-26.

22. Rouvas A, Stavrakas $P$, Theodossiadis PG, Stamatiou P, Milia M, Giannakaki E, et al. Long-term results of half-fluence photodynamic therapy for chronic central serous chorioretinopathy. Eur J Ophthalmol. 2012;22:417-22.

23. Nicolo M, Zoli D, Musolino M, Traverso CE. Association between the efficacy of half-dose photodynamic therapy with indocyanine green angiography and optical coherence tomography findings in the treatment of central serous chorioretinopathy. Am J Ophthalmol. 2012;153:474-80.

24. Zhao MW, Zhou P, Xiao HX, Lv YS, Li CA, Liu GD, et al. Photodynamic therapy for acute central serous chorioretinopathy: the safe effective lowest dose of verteporfin. Retina. 2009;29:1155-61.

25. Zhao MW, Zhang F, Chen Y, Dai H, Qu J, Dong C, et al. A 50\% vs 30\% dose of verteporfin (photodynamic therapy) for acute central serous chorioretinopathy one-year results of a randomized clinical trial. JAMA Ophthalmol. 2015:133:333-40.

26. Liu CF, Chen LJ, Tsai SH, Lai CC, Chan WC, Wu WC, et al. Half-dose verteporfin combined with half-fluence photodynamic therapy for chronic central serous chorioretinopathy. J Ocul Pharmacol Ther. 2014 Jun;30:400-5.

27. Uetani R, Ito $Y$, Oiwa K, Ishikawa K, Terasaki H. Half-dose vs one-third-dose photodynamic therapy for chronic central serous chorioretinopathy. Eye. 2012;26:640-9

28. Maruko I, lida T, SuganoY FM, Sekiryu T. One-year choroidal thickness results after photodynamic therapy for central serous chorioretinopathy. Retina. 2011:31:1921-7.

\section{Publisher's Note}

Springer Nature remains neutral with regard to jurisdictional claims in published maps and institutional affiliations.
Ready to submit your research? Choose BMC and benefit from:

- fast, convenient online submission

- thorough peer review by experienced researchers in your field

- rapid publication on acceptance

- support for research data, including large and complex data types

- gold Open Access which fosters wider collaboration and increased citations

- maximum visibility for your research: over $100 \mathrm{M}$ website views per year

At BMC, research is always in progress.

Learn more biomedcentral.com/submissions 